\title{
Window of Opportunity
}

\author{
Oratie uitgesproken op 25 Februari 2022 \\ Prof. Dr. Loes Keijsers
}

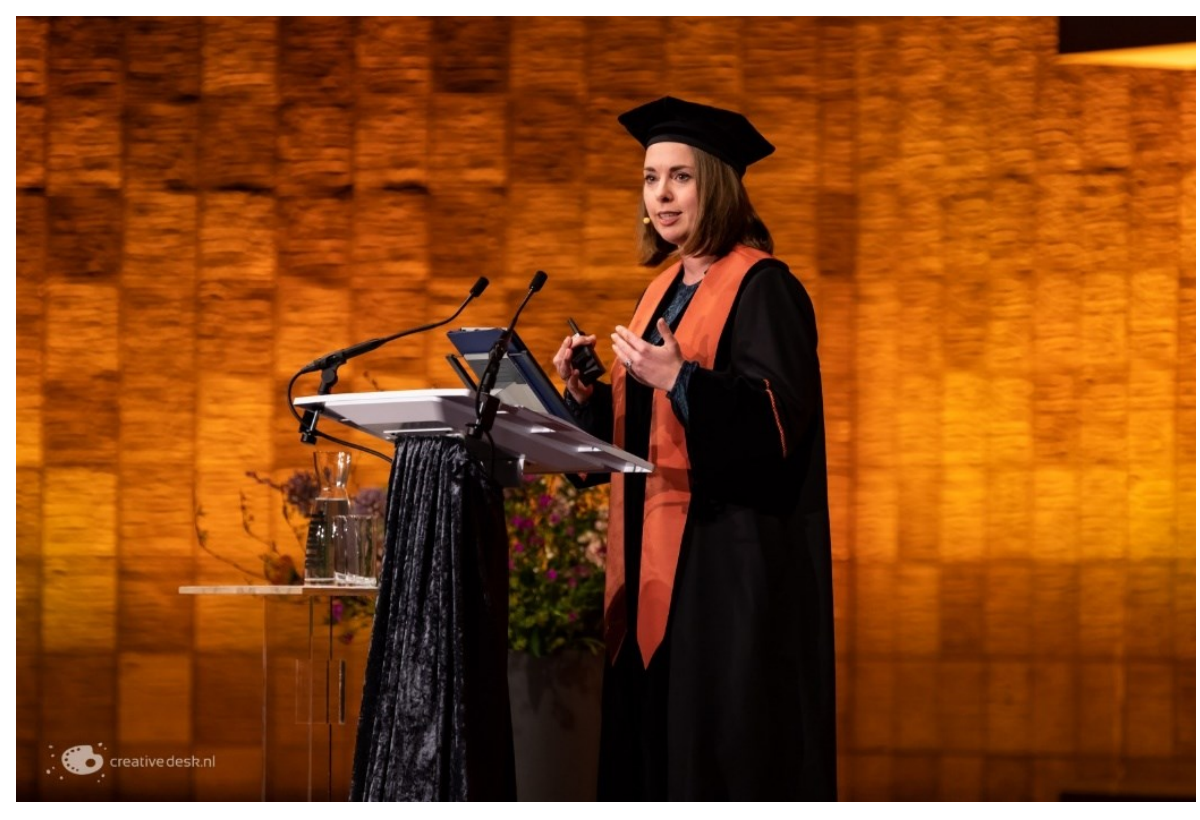

Erasmus Universiteit Rotterdam

Faculty of Social and Behavioral Sciences 
Mevrouw de rector magnificus, mijnheer de decaan van de Erasmus School of Social and Behavioural Sciences, geachte toehoorders, beste collega's, lieve vrienden en familie, hier aanwezig of online.

Dit ben ik: 25 jaar geleden. Ik heb zojuist demonstratief met mijn ogen gerold, omdat mijn vader een foto wilde nemen van ons gelukkige gezinnetje. We hebben net 3.5 uur geslenterd door een oud stadje ergens in Italië. Het is 32 graden en mijn voeten doen pijn. Dus ik heb geen zin in een obligaat vakantiekiekje - Sterker nog: ik heb nergens zin in. Ik ben namelijk 14 en een puber.

Herkent u dit van toen u zelf puber was? Rolde u ook wel eens met uw ogen? Of zijn uw ervaringen helemaal anders?

Elk mens is uniek. We hebben allemaal ons eigen unieke levensverhaal. Toch zijn er ook veranderingen waar ieder mens door heen gaat: Op de ene of andere manier zijn we allemaal volwassen geworden. De periode tussen de 12 en 25 jaar, is voor kinderen wereldwijd een cruciale overgangsfase tussen de kindertijd en volwassenheid. We noemen hem de adolescentie. In de adolescentie word je wie je bent en later zult zijn. Het is een belangrijke "window of opportunity" voor lichamelijke, sociale, cognitieve en persoonlijke groei.

Dus laten we eens kijken. Hoe gaat het met onze jeugd? Het korte antwoord is: Dat hangt er vanaf naar welke bron je kijkt en aan welk kind je het vraagt. Nederlandse kinderen worden vaak gezien als de gelukkigste van de wereld (PISA, 2018). Maar tegelijkertijd toont ander onderzoek een toename in angststoornissen en depressie. Covid heeft deze situatie verslechterd, met alleen al in Nederland een geschatte toename van $25 \%$ in depressieve stoornissen. De adolescentie is een gevoelige fase voor het ontstaan van problemen. 75\% van stoornissen in de ontwikkeling, zoals angst, depressie of ADHD ontstaan al voor het 24e levensjaar.

In grote lijnen geldt: Kom je goed door de adolescentie, dan heb je goede kaarten voor de volwassenheid. Andersom geldt helaas ook: Ontstaan er problemen in deze belangrijke fase, dan kan je daar een leven lang last van hebben. Door mentale problemen vallen jongeren bijvoorbeeld uit op school of raken betrokken bij criminaliteit. Verschillen tussen jongeren onderling worden zo uitvergroot in de adolescentie. We moeten dus beter gaan begrijpen hoe deze cruciale levensfase, deze window of opportunity, eraan bijdraagt dat jongeren juist positief, mentaal gezond, en veerkrachtig volwassen worden, of mentale problemen ontwikkelen en uitvallen.

En het is in ieders belang dat we er zo vroeg mogelijk bij zijn als er problemen in de ontwikkeling ontstaan. Is het niet om het persoonlijke leed van kinderen en families te verzachten, dan moeten we het doen voor de maatschappij als geheel.

Onze jongeren zijn de levende toekomst van de wereld. Zij krijgen als generatie grote uitdagingen voor zich, die wij, de volwassene van nu, hen achterlaten:

Zij zullen een oplossingen moeten vinden voor klimaatproblemen.

Zij worden hard geraakt door toenemende ongelijkheid bijv. op de woningmarkt. 
Zij zullen in de toekomst moeten zorgen voor ons, dan een grote groep ouderen met kwaaltjes en kuren.

Elke euro die we NU investeren in het voorkomen van problemen in de adolescentie, verdient zich LATER dik en dubbel terug. Investeren in de jeugd loont.

Maar voordat ik u meer vertel over hoe ik daar met mijn leerstoel aan zal bijdragen waarom we met andere ogen moeten gaan kijken, en hoe nieuwe technologie een rol kan spelen bij het zoeken naar oplossingen neem ik graag mee naar de wondere wereld van de adolescentie en naar mijn mooie vakgebied: de pedagogiek.

Zoals Erasmus al opmerkte: "mensen ... worden niet geboren maar gevormd." We groeien op en worden door schade en schande wijs. Problemen in de ontwikkeling van gevoelens en gedrag ontstaan niet van de een op de andere dag. Er ligt altijd een complexe wisselwerking aan ten grondslag, tussen aanboren kwetsbaarheden en omgevingsfactoren. Van macro-invloeden zoals cultuur, of de buurt waarin je opgroeit, tot meer directe dagelijkse invloeden van ouders, vrienden en sociale media. In mijn werk stel ik een klassieke vraag in de pedagogiek: Hoe kan je als ouder je puberende kind veilig en gezond door de adolescentie loodsen.

Wanneer doe je het als ouder goed? Jarenlang onderzoek suggereert drie belangrijke kenmerken van een goede opvoeding.

Ten eerste, hoe meer steun en betrokkenheid ouders tonen in het leven van een kind, hoe kleiner de kans dat het kind problemen ontwikkelt. Ten tweede, duidelijke regels zijn belangrijk. Jongeren die bijvoorbeeld te horen krijgen dat drinken onder de 18 niet mag, drinken minder. Ten derde, ouders die jongeren ondersteunen in hun eigen autonomie-ontwikkeling, hebben kinderen die niet alleen beter hun eigen keuzes kunnen maken, maar ook minder depressieve klachten hebben. Steun, duidelijke regels, en autonomie ondersteuning vormen. Samen de drie kerningrediënten van opvoeding van pubers.

Ook mijn eigen empirische onderzoek heeft deze inzichten lang ondersteund. Tot voor kort. Want deze harde conclusies lijken toch minder sterk dan dat we lang dachten. Om dat te verhelderen, moet ik u eerst iets meer vertellen over onze manier van onderzoek doen. Want hoe weten we bijvoorbeeld dat een warme opvoeding, met veel steun van ouders, beschermt tegen depressie?

Een belangrijk onderzoeksmethode in de pedagogiek en ook in andere sociale wetenschappen, is het verzamelen van data, bijvoorbeeld met vragenlijsten, observaties, of diagnostische interviews.

Dit doen we dan niet bij alle jongeren in Nederland, maar bij een groep, een steekproef. Het achterliggende idee is, dat als we begrijpen hoe de processen werken in een bepaalde groep jongeren, die een goede representatie is van alle jongeren, dat we dan ook de andere jongeren begrijpen. Dus laten we eens zien.

Hier heb ik een kleine steekproef van jongeren. 9 stuks. 
Zij doen mee aan onderzoek, en vullen vragenlijsten in over depressieve gevoelens en steun van ouders. Deze meid, laten we haar Lauren noemen, vulde een vragenlijst in, en hieruit bleek hoe ze zich voelde en hoe steunend haar ouders waren. Het volgende kind, Bastiaan, heeft dit ook gedaan, en scoorde net even anders. En zo krijgen we voor elke jongere twee datapunten. Eentje voor hoe het kind zich voelt, en eentje voor de opvoeding. Om nu te achterhalen of er een verband is tussen hoe ouders opvoeden en hoe het gaat met het kind, gebruiken we statistische analyses. Hier bijvoorbeeld berekenen we een correlatie tussen steun van ouders en depressieve gevoelens. Deze is negatief. Daaruit blijkt dat jongeren die meer steun ervaren van hun ouders dan andere kinderen, minder kans hebben op depressieve gevoelens dan leeftijdsgenoten.

In de afgelopen 60 jaar zijn er duizenden studies gedaan met als basis dit soort onderzoek, dat ik nu vereenvoudigd weergeef. We noemen dit een nomothetische aanpak. Op dit moment ontstaan er barstjes in dit onderzoeksparadigma, waarin we onderzoek doen naar algemene principes op groepsniveau, en dus iets leren over het gemiddelde kind, en het gemiddelde gezin.

Want wat als elk kind uniek is? Wat als het ene kind positief reageert op steun van ouders, en het andere kind er juist meer depressieve gevoelens van ontwikkelt? Wat als de gouden standaard niet bestaat? Heeft het dan wel zin om te kijken naar gemiddelden? Bestaat het gemiddelde kind überhaupt wel? Er spelen gelijktijdig drie typen kritieken op, die suggereren dat we verder moeten kijken dan groepen en het groepsgemiddelde. Dat juist het individu ons uitgangspunt zou moeten zijn.

De eerste type kritiek die steeds vaker klinkt op onderzoek naar groepsgemiddelden is theoretisch.

En dan laat zich het beste illustreren met een persoonlijke ontboezeming. Ik heb een tweelingzus. Karen. Ze zit hier op de eerste rij. We zijn vrijwel helemaal hetzelfde. Ons DNA is identiek, onze opvoeding was bijna hetzelfde, we gingen naar dezelfde school.

Volgens klassieke theorieën, die algemene principes van ontwikkeling beschrijven, zouden we ons precies hetzelfde moeten gedragen. Toch is dat niet zo - althans, niet altijd zo. Want terwijl ik mij tijdens mijn puberteit specialiseerde in het rollen van mijn ogen naar mijn ouders, ging haar alles voor de wind.

Hoe kan dat zo zijn?

Meer recentere theorieën in de ontwikkelingspsychologie en pedagogiek helpen ons hierbij een handje. Deze gaan er juist vanuit gaat dat elk kind, op een unieke manier wordt gevormd door invloeden van buitenaf. In andere woorden, ook al ben je identiek bij geboorte, dan nog ontwikkelt elk kind anders.

Als deze theorieën kloppen, dan is het minder zinvol om onderzoek te doen naar het gemiddelde kind. Dan moeten we op zoek naar hoe het individu functioneert. Dan moeten we per kind op zoek gaan naar de unieke factoren die verklaren hoe het kind zich voelt, gedraagt en denkt in het dagelijkse leven. 
Ook in de klinische praktijk is algemeen bekend dat geen kind hetzelfde is. "onesize-fits-all" benaderingen die gebaseerd zijn op algemene principes werken niet altijd optimaal. Soms zelfs averechts bij een subgroep. De praktijk heeft dus behoefte aan meer maatwerk oplossingen. Maar hoe kan je opvoedprogramma's of andere interventies aanbieden die precies aansluiten bij elk unieke kind, en elk gezin. De meeste theoretische kennis, immers, is nog altijd gebaseerd op algemene principes.

Ten derde, al bijna een eeuw benadrukken wetenschappers dat onderzoek zou moeten gaan over echte gedrag en echte mensen. Meer recent benadrukken methodologen zoals Peter Molenaar dat groepsgemiddelden een vertekend beeld geven van de processen die plaatsvinden in individuele jongeren en gezinnen.

Samengevat, klinken er drie typen kritiek op onderzoek naar algemene principes van opvoeding en ontwikkeling: Theoretisch, praktisch en methodologisch. Het klinkt uit elke hoek.

Maar dan de hamvraag: Als theoretici, behandelaars en methodologen het eens zijn dat we ons moeten richten op het individu, waarom doen we dat dan niet? Waarom kijken we niet verder dan het groepsgemiddelde?

Het ontnuchterende antwoord is, dat het tot voor kort vrijwel onmogelijk was om dat te doen. En om voldoende data te verzamelen van echt gedrag, van echte mensen, in echte omstandigheden om per mens te begrijpen hoe deze in elkaar zit. Er waren wel uitzonderingen, die een dappere poging hebben gewaagd. Charles Darwin en Jean Piaget hebben bijvoorbeeld hun eigen kinderen jarenlang geobserveerd. Reed Larson doet al bijna vijftig jaar baanbrekend onderzoek met dagboekjes bij andermans kinderen. Hij vraagt jongeren meerdere keren per dag noteren wat ze aan het doen zijn, met wie ze zijn en hoe ze zich voelen. Dit is monnikenwerk. En dat werd dus altijd gedaan bij maar een of een paar kinderen. Tot voor kort.

We hoeven als onderzoekers niet elk gezin een notitieboekje mee te geven. Of per gezin mee te lopen, en kind per kind te volgen. Jongeren en ouders hebben een onderzoeksdevice in hun broekzak. Hun smartphone. We kunnen nu tegelijkertijd tientallen tot honderden jongeren en ouders meerdere keren per dag meten.

En dat biedt, ons onderzoekers, een unieke window of opportunity.

Een vragenlijst, immers, dat is een abstractie - een momentopname - een foto. We vragen bijvoorbeeld hoe de relatie was het afgelopen jaar. 365 dagen, 1000 en interacties, tientallen momenten waarin je lacht of elkaar in de haren vliegt. gevangen in 1 getal.

Met apps vragen we gezinnen meerdere keren per dag wat ze meemaken, of ze lekker hebben geslapen, hoe ze zich voelen na een ruzie, en wat ze denken over elkaar. Met deze nieuwe aanpak vragen krijgen we wel 50, 100, of nog meer korte momentopnames van elk gezin, van elke ouder en kind. En daarmee krijgen we opeens een full color film krijg te zien wat er allemaal speelt achter de voordeur van individuele gezinnen en individuele kinderen. 
Hier bijvoorbeeld toon ik data van 1 kind dat 120 keer bijhield hoe ze zich voelde in ons onderzoek. Haar welbevinden, hoe lekker dat ze in haar vel zat dat fluctueerde van moment tot moment. Soms was ze blij, soms wat minder. Dat toont de rode lijn. En hoeveel steun ze ervaarde van ouders ook. Het ene moment vond ze haar ouders erg steunend. Het andere moment juist niet. Dat is de witte lijn.

Wat je ziet, is dat hoe het kind zich voelt, en wat ouders doen samen op en af gaan. Ze zijn gecorreleerd, binnen dit ene kind. Op momenten van meer steun, voelt dit kind zich beter. En op momenten met minder steun, juist minder goed. Met nieuwe typen statistiek kunnen per uniek gezin, vaststellen hoe precies opvoeding samenhangt met hoe dit specifieke kind zich voelt.

Wat ik met dit soort nieuwe data samen met mijn collega's en samenwerkingspartners heb ontdekt de afgelopen jaren, door met dit soort andere ogen te kijken, en nieuwe methoden in te zetten, vertel ik u nu graag.

Als eerste wilde ik weten hoe opvoeding samenhangt met gedragsproblemen, zoals jeugddelinquentie. Veel onderzoek laat zien dat als ouders meer interesse tonen in hun kind en dus beter monitoren wat hun kind doet op straat en met vrienden dat kinderen dan minder delinquent zijn. Het verbeteren van monitoring door ouders is dan ook een belangrijke component van opvoedinterventies.

Maar toen ik in 2015, geïnspireerd door het methodologische werk van Ellen Hamaker, een nieuw type analyses draaide kwam ik tot een ontnuchterende andere conclusie. Op momenten dat ouders meer vragen stelden of dat ouders duidelijkere regels hanteerden waren kinderen niet minder delinquent. Ik vond geen verband binnen gezinnen. Dat was verrassend.

En toen ik verder ging inzoomen bleek ook waarom. In het RADAR onderzoek vulden 479 families 15 weken een online dagboekjes in. Daaruit bleek dat de monitoringsprocessen anders waren van gezin tot gezin: In sommige gezinnen vertelden kinderen bijvoorbeeld meer als hun ouders meer vragen stelden. In andere juist minder.

Ik zag waarschijnlijk niets op het gemiddelde niveau, omdat een groepsgemiddelde grote verschillen tussen gezinnen maskeert. Deze eerste studies suggereerden dat de invloed van ouders op gedragsproblemen zoals delinquente en agressie, wel eens anders zou kunnen zijn van gezin tot gezin, al moet toekomstig onderzoek dit bevestigen.

Een tweede belangrijke domein van functioneren van jongeren is hun emotionele welbevinden, of ze lekker in hun vel zitten en tevreden zijn over het leven bijvoorbeeld. Opvoeding speelt daarbij een belangrijke rol, met name steun van ouders, warmte. Samen leuke dingen doen, betrokkenheid voelen en een goed gesprek; Uit jarenlang onderzoek weten we dat jongeren die meer steun krijgen van hun ouders (ten opzichte van andere gezinnen) beter in hun vel zitten. Dat blijkt ook steeds uit mijn eigen werk. 
Maar zijn dit universele principes die gelden voor elk gezin? Of geeft ook hier het groepsgemiddelde een vertekend beeld?

In het ADAPT project onderzoeken Anne Bülow en Savannah Boele het dagelijkse leven van gezinnen om deze vraag te beantwoorden. We meten wel 5 tot 6 keer per dag hoe jongeren zich voelen, en hoe hun ouders hen opvoeden. Van uur tot uur krijgen we zo inzicht in het reilen en zeilen van families, en hoe opvoeding het welbevinden kind beïnvloeden kan. En wat blijkt?

De meeste kinderen voelen zich beter op momenten dat hun ouders meer steun geven, en er minder conflicten zijn. Maar als we drie uur later kijken zien we een ander beeld. Dan voelt 38\% van de kinderen zich beter nadat ze meer warmte hadden ervaren, en 19\% voelt zich slechter. 19\% voelt zich slechter nadat hun ouders warmer en meer betrokken waren, en dat staat dus haaks op de theorie. Dat was verrassend. Er zijn grote verschillen tussen kinderen in wat steun van ouders doet met hen.

In een dagboekstudie onder 242 jongeren beschrijft Loes Janssen soortgelijke bevindingen. In 90\% van de gezinnen voelen jongeren zich beter op dagen dat hun ouders meer steun geven. Zoals verwacht. Maar in 10\% van de gezinnen was het patroon andersom. Deze kinderen voelen zich juist slechter op dagen dat hun ouders meer steun geven.

Deze eerste studies tonen het volgende:

Gemiddeld genomen kinderen gaat het beter met kinderen als hun ouders meer monitoren en meer steun geven - en in veel gezinnen werkt het ook zo op dagdagelijkse basis. Maar de eerste bevindingen tonen ook twee opmerkelijke dingen.

1) dynamieken tussen ouders en kinderen kunnen best wel sterk verschillen van gezin tot gezin

2) algemene principes schieten daarmee soms te kort schieten om echt te begrijpen wat unieke jongeren en hun ouders meemaken met elkaar tijdens de puberteit.

Deze overkoepelende vraag welke principes van ontwikkeling universeel zijn, en welke anders zijn van kind tot kind, is bovendien veel breder dan alleen de opvoedingsliteratuur. In project Awesome, onder leiding van Patti Valkenburg, onderzoeken we bijvoorbeeld de invloed van sociale media op jongeren. We toonden de afgelopen jaren dat elk kind op unieke wijze wordt beïnvloed door hun sociale media gebruik: Sommige voelen zich beter nadat ze op sociale media zaten, anderen juist slechter. Ook George Aalbers toont dit soort unieke processen aan in zijn recente werk. Ook in dit domein zijn er maar weinig jongeren zich gedragen volgens de algemene theorieën. Wederom is elk kind uniek.

Feitelijk hebben we dus twee typen theoretische inzichten nodig over ontwikkelende jongeren- algemene kennis over wat beschermende of risicofactoren zijn op populatieniveau. OF wat de belangrijke dimensies zijn van 
opvoeding die we zouden moeten bestuderen. Maar per kind hebben we ook persoonsspecifieke kennis nodig over hoe deze potentieel belangrijke omgevingsfactoren inwerken op het individu en hoe we ze kunnen veranderen.

Terwijl we op het gebied van dit eerste soort kennis hebben grote vooruitgang hebben geboekt in de afgelopen 70 jaar, staat de pedagogiek nog in de kinderschoenen als het gaat om het in kaart brengen van hoe ontwikkelingsprocessen verschillen. Je zou kunnen zeggen dat ons vakgebied in een methodologische puberteit zit.

We gaan een groeispurt maken de komende jaren. Door met nieuwe technologieën het dagelijkse leven van individuele kinderen te onderzoeken. Met mijn leerstoel zal ik bijdragen aan nieuwe theoretische inzichten over hoe unieke kinderen verschillen van elkaar.

Maar dan de hamvraag voor velen: Wat kunnen we hiermee in de praktijk?

One size doesn't fit all. Het lijk zo'n open deur. Zelfs een toga, waarbij toch de intentie is dat iedereen precies op elkaar lijkt, laten we op maat maken. Ook in de klinische praktijk is maatwerk nodig. Als het niet goed gaat met een kind, bijvoorbeeld om het kind veel agressie laat zien, of depressie heeft ontwikkeld dan moet je soms ingrijpen - maar de oorzaken zijn anders van kind tot kind. Het ene kind wordt depressief van stress op school. Bij het andere kind speelt de opvoeding een rol.

Om per individueel kind en per gezin in kaart te brengen hoe het precies werkt, en daarop in te grijpen met de meest geschikte behandeling. Hiervoor heeft een professional jarenlange opleiding en werkervaring nodig. Dit soort precisie, dit soort maatwerk, is zeer kostbaar.

Mat wat als er nog geen problemen zijn? Kunnen we ze voorkomen? Het is dan niet haalbaar, noch wenselijk, om elk kind een eigen specialistische zorgverlener te geven. Preventie is grootschaliger, en daarom vrijwel altijd gebaseerd op algemene principes, waarvan we uitgaan dat het voor elk kind zal werken.

Maar... waarvan we nu steeds meer twijfelen of dat nu wel altijd toepasbaar is op echte mensen, met al hun unieke eigenschappen. Grootschaligheid en maatwerk. Het laat zich vooralsnog lastig combineren.

Toch is dat wel de "golden bullet" van preventie-onderzoek. Maatwerk voor de massa. Deze uitdaging ben ik aangegaan samen met Manon Hillegers en de vele collega's, waaronder promovendi Michelle Aukes en Evelien Dietvorst. Samen ontwikkelden we de Grow It! app. Een serious game die leuk is om te spelen, en je ook nog eens helpt.

Als jongeren Grow It! spelen vullen ze meerdere keren per dag in hoe ze zich voelen, wat ze aan het doen zijn, en waar ze zijn. Deze data zien ze direct terug in hun eigen emotie-profiel dat is gebaseerd op geautomatiseerde data-analyses. Zo leren ze zichzelf beter kennen - in real-time. 
Zo kan de ene puber leren dat bij haar slaapgebrek haar chagrijnig maakt. En de ander jongeren zou kunnen leren dat hij meer negatieve emoties heeft op maandagochtend dan op vrijdagmiddag.

Ook kiezen jongeren elke dag een challenge uit, die hen aanspoort om bijvoorbeeld naar buiten te gaan, vrienden op te zoeken, sorry te zeggen, of iets creatiefs te doen. Deze opdrachten hebben we samen met jongeren ontwikkeld. Door iets te doen wat ze normaal niet zouden doen, breiden ze hun persoonlijke gereedschapskist van strategieën uit om met stress om te gaan.

Meer dan 2000 jongeren hebben de app nu gespeeld tijdens de lockdowns van 2020 en 2021. De eerste bevindingen suggereren voorzichtig dat de app effect heeft: Jongeren kregen na 3 tot 6 weken spelen een meer positief welbevinden, en hun angst en depressie nam af. In de komende jaren gaan we hier mee door.

Binnen het eHealthJr consortium doen we bijvoorbeeld onderzoek waarbij we ook een controlegroep meenemen - Dat zou moeten uitwijzen of de app echt werkt, maar ook voor wie wel, en voor wie niet.

De komende jaren zijn er volop kansen voor eHealth - en hebben we als wetenschappers een unieke window of opportunity om doorbraken te forceren samen met de praktijk: Smartphone apps en andere draagbare technologieën ontwikkelen snel en de rekenkracht van computers zal verder toenemen.

We weten nog lang niet alles, en zullen nog veel moeten onderzoeken, maar toch zijn de eerste resultaten hoopgevend. Ze suggereren dat soms maatwerk, toch grootschalig inzetbaar is om problemen zo vroeg mogelijk tegen te gaan, of liever nog, te voorkomen dat ze ontstaan.

Want dat is uiteindelijk het doel wat ik heb als Erasmiaanse wetenschapper. Niet alleen de complexiteit van oorzaken van de grote maatschappelijke problemen beter begrijpen, maar ook bijdragen aan oplossingen. Beide grote uitdagingen vergen een andere wetenschappelijke benadering en attitude.

Om dit toe te lichten neem ik u mee in twee verhalen, met twee stoere pubers, die leven in twee totaal verschillende werelden. Misschien kent u ze wel....

Als eerste stel ik u voor aan Alice. Zij vertegenwoordigt de meer klassieke uitdaging voor de wetenschap: Het begrijpen van problemen. De jonge meid uit het verhaal van Lewis Caroll valt in een konijnenhol. Daar verdwaalt ze in een wondere wereld. Ze probeert een flesje, en ze groeit. Ze doet iets anders en ze krimpt. Alice is een nieuwsgierigheidsgedreven wetenschapper die nieuwe vragen durft te stellen, experimenteert en zich verwondert. Dat sprookje, dit wonderland, moeten we koesteren - daar zijn werelds mooiste ontdekkingen uit voortgekomen.

Maar "If you dont know where you are heading any direction is fine". Zonder duidelijke stip op de horizon kost het vaak enkele decennia van nieuw theoretisch inzicht tot werkende interventie. Dit is tijd die we niet altijd krijgen of hebben. Want we hebben ook oplossingen nodig. Vanuit het perspectief van de jongere gesproken: Liefst snel een beetje. 
Er gaan dus wel eens stemmen op dat wetenschappers hun kostbare tijd veel beter direct zouden kunnen inzetten voor het creëren van oplossingen. Dit type benadering heet ook wel impact-gedreven wetenschap. En dat vraagt een andere wetenschappelijke benadering en attitude.

Daarom stel ik u nu graag voor aan Dorethy, uit Texas, maar u kent haar wellicht beter van de Wizard of Oz. Dorethy heeft een probleem. Haar huis is door een tornado weggeblazen. Ze belandt in magische land van Oz en wil naar huis. lemand suggereert dat de Wizard - de tovenaar - voor alles een oplossing heeft. Ze gaat direct op zoek - ze is nogal een doener van aard.

Gaandeweg ontmoet ze vrienden, een leeuw zonder lef. Een blikken man (wat we nu een robot zouden noemen) zonder hart. En een vogelverschrikker zonder brein. Samen lopen ze, hand in hand, de gele weg af naar de oplossing. Dorethy is wat dat betreft een echte impact-onderzoeker die het probleem centraal stelt, en door samen te werken met andere disciplines haar doel bereikt. Aangekomen, echter, bij deze Wizard blijkt dat hij eigenlijk gewoon een charlatan is. Een fopoplossing. Had Dorethy maar wat meer vragen gesteld onderweg - net even iets vaker stil gestaan en getwijfeld. Hadden ze ook maar een fundamentele nieuwsgierigheid gedreven onderzoeker zoals Alice in hun team gehad - dan was het wellicht niet gebeurd.

Dorethy en Alice. Beide staan ze voor mij symbool voor twee uiteinden van een continuüm van wetenschap - van fundamenteel naar impact-gedreven. Het lijken soms twee verschillende werelden. Maar voor mij is dit een schijndichotomie. Met mijn leerstoel zal ik gelijktijdig werken aan het beter begrijpen van het probleem en het bedenken en toetsen van nieuwe slimmere oplossingen die jongeren helpen.

Ik zal hiertoe vol inzetten op samenwerking met andere disciplines, en ik sluit ook zeer enthousiast aan bij de strategische convergentie tussen EUR, EMC, en TUDelft. De denkers en de doeners. De dokters, de data-wetenschappers, de designers Samen kunnen we veel bereiken - en dat gaan we ook doen.

Maar ik zal ook steeds opnieuw hardop twijfelen of ik met mijn onderzoek wel op de goede weg zit. Door vragen te blijven stellen aan jongeren, hun ouders en maatschappelijke partners. Van hen leren we wat er speelt, en wat de belangrijkste thema's van fundamenteel onderzoek zijn. Excellent wetenschappelijk onderzoek vertalen naar zinvolle oplossingen. Dat is hoe ik het zie: Wetenschap, midden in de maatschappij. Als verbinder.

Tot slot, neem ik u graag mee terug naar de vraag die mij persoonlijk al 25 jaar bezighoudt en de laatste 15 jaar van onderzoek heeft bepaald: Hoe zorgen we er voor dat jongeren gezond en wel opgroeien - en hoe kunnen ouders optimaal bijdragen aan deze window of opportunity.

De pedagogiek zal als vakgebied, net als pubers in de adolescentie, een fascinerende groeispurt gaan doormaken - waarin we niet alleen de algemene principes beter kunnen begrijpen, maar ook het individuele kind en gezin. 
Met nieuwe technologieën kunnen we eindelijk het dagelijkse leven in al haar rijkheid bestuderen. Daarmee kunnen we per gezin ontrafelen hoe opvoeding samenhangt met ontwikkeling van het kind.

Dat is niet alleen theoretisch fascinerend, maar kan aanleiding geven voor grootschalige maatwerkoplossingen om ontwikkelingsproblemen vroegtijdig te behandelen en hopelijk zelfs te kunnen voorkomen. Ik hoop dat u samen met mij dit avontuur wil aangaan, om zo elke jongere, elk uniek mens, optimale kansen te geven op een lang en gelukkig leven.

\section{Dankwoord}

Gelukkig hoef ik dat niet alleen te doen, en ik voel me gezegend en dankbaar dat deze fantastische Rotterdamse academische omgeving mij hiertoe alle kansen biedt.

Mijn grote woorden van dank gaan uit naar het college van bestuur, decaan Victor Bekkers, Vice-decanen Semiha Denktas en Bram Steijn, de leden de benoemingscommissie. Dank voor jullie vertrouwen. Mijn directe collega's van DPECS en mijn leidinggevende Katinka Dijkstra. Door jullie voel ik me elke dag geïnspireerd en aangemoedigd. Ik dank ook de collega's van ondersteunende diensten. Ook vandaag zou ik niets zijn zonder jullie.

En dan mijn academische thuis-basis: de sectie Ortho- en Gezinspedagogiek. Wat is het fantastisch om elke dag samen met jullie de mouwen op te mogen stropen voor excellent onderzoek, en innovatief onderwijs. Dank voor de warme ontvangst afgelopen jaar. En dank voor onze fijne en gezellige samenwerking. Elke dag.

Ook mijn samenwerkingspartners van eHealthJr, in het bijzonder Manon Hillegers. Dank voor de jarenlange krachtige verbinding. En mijn Amsterdamse collega's, onder leiding van Patti Valkenburg: You are simply Awesome.

Een bijzonder woord van dank voor alle jonge onderzoekers, aio's en postdocs die ik mag begeleiden. Niets is leuker dan samen met jullie puzzelen om echt te snappen hoe pubers opgroeien. Dank ook aan de projectmanagers die mijn rechterhand zijn geweest, en vaak ook mijn linker, in het waarmaken van mijn grote dromen. Vandaag sta ik hier om te vertellen wat we samen al hebben ontdekt, door team-work, en wat we nog willen gaan doen.

Ook buiten Rotterdam heb ik de afgelopen jaren mogen samenwerken met zo veel hartelijke, slimme, fijne collega's. In het bijzonder noem ik Susan Branje en Wim Meeus, mijn promotoren. Jullie zijn mijn academische ouders, en ik ben heel dankbaar voor het sterke fundament wat jullie me hebben meegegeven. Dank allen voor jullie mentorschap, wijsheid, en gezelligheid. Alle vonkjes die jullie al hebben overgebracht op mij, en zullen gaan overbrengen in de komende jaren. Ik heb er veel van geleerd, en ik zie er naar uit.

Tot slot, ik ben niet alleen wetenschapper. Ik ben omringd door nog veel meer unieke en bijzondere mensen in mijn leven. Dierbare vrienden, familie en aangetrouwde familie. Jullie zijn mijn thuisbasis. Twee fantastische zussen; Anke en 
Karen. Zes stoere neefjes en nichtjes die vast en zeker de leukste pubers van de wereld gaan worden.

En tot slot, mijn nieuwsgierige en hardwerkende ouders en mijn allerliefste man, Victor. Jullie hebben me gevormd. Door jullie heb ik wortels en door jullie heb ik vleugels gekregen. Bij jullie mag ik helemaal mezelf zijn en worden.

Ik heb gezegd 


\section{Wilt u meer lezen over dit onderzoek?}

Onderstaande studies van mijn collega's en mij worden in dit verhaal besproken. Allen zijn gratis online te downloaden via Google Scholar.

Aalbers, G., vanden Abeele, M. M., Hendrickson, A. T., De Marez, L., \& Keijsers, L. (2022). Caught in the moment: Are there person-specific associations between momentary procrastination and passively measured smartphone use?. Mobile Media \& Communication, 10(1), 115-135.

Boele, S., Denissen, J., Moopen, N., \& Keijsers, L. (2020). Over-time fluctuations in parenting and adolescent adaptation within families: a systematic review. Adolescent Research Review, 5(3), 317-339.

Bülow, A., van Roekel, E., Boele, S., Denissen, J., \& Keijsers, L. (2022). Parent-adolescent interaction quality and adolescent affect-an experience sampling study on effect heterogeneity. Child Development

Beyens, I., Pouwels, J. L., van Driel, I. I., Keijsers, L., \& Valkenburg, P. M. (2020). The effect of social media on well-being differs from adolescent to adolescent. Scientific Reports, 10(1), 1-11.

Dietvorst, E., Aukes, M., Legerstee, J., Vreeker, A., Hrehovcsik, M., Keijsers, L., \& Hillegers, M. (2022). The developmental process, feasibility and acceptance of the Grow It! app: a smartphone serious game for adolescents. JMIR

Janssen, L. H., Elzinga, B. M., Verkuil, B., Hillegers, M. H., \& Keijsers, L. (2021). The link between parental support and adolescent negative mood in daily life: between-person heterogeneity in within-person processes. Journal of youth and adolescence, 50(2), 271-285.

Keijsers, L., Voelkle, M. C., Maciejewski, D., Branje, S., Koot, H., Hiemstra, M., \& Meeus, W. (2016). What drives developmental change in adolescent disclosure and maternal knowledge? Heterogeneity in within-family processes. Developmental Psychology, 52(12), 2057.

Keijsers, L. (2016). Parental monitoring and adolescent problem behaviors: How much do we really know?. International Journal of Behavioral Development, 40(3), 271-281.

Keijsers, L., Boele, S., \& Bülow, A. (2022). Measuring parent-adolescent interactions in natural habitats. The potential, status, and challenges of ecological momentary assessment. Current opinion in psychology, 44, 264269.

Pouwels, J. L., Valkenburg, P. M., Beyens, I., van Driel, I. I., \& Keijsers, L. (2021). Social media use and friendship closeness in adolescents' daily lives: An experience sampling study. Developmental Psychology, 57(2), 309.

Valkenburg, P., Beyens, I., Pouwels, J. L., van Driel, I. I., \& Keijsers, L. (2021). Social media use and adolescents' self-esteem: Heading for a person-specific media effects paradigm. Journal of Communication, 71(1), 56-78.

van Roekel, E., Keijsers, L., \& Chung, J. M. (2019). A review of current ambulatory assessment studies in adolescent samples and practical recommendations. Journal of Research on Adolescence, 29(3), 560-577.

\section{Inspirerend werk van anderen}

Hamaker, E. L., Kuiper, R. M., \& Grasman, R. P. (2015). A critique of the cross-lagged panel model. Psychological methods, 20(1), 102.

Larson, R. W. (2019). Experiencing sampling research from its beginnings into the future. Journal of Research on Adolescence, 29(3), 551-559

Molenaar, P. C. (2004). A manifesto on psychology as idiographic science: Bringing the person back into scientific psychology, this time forever. Measurement, 2(4), 201-218. 